\title{
CT EKSPIRASI RESOLUSI TINGGI: KEGUNAAN DIAGNOSTIKNYA PADA PENYAKIT PARU DIFUS
}

\section{Gayathrie Chantrhira Sakaran}

Program Studi Pendidikan Dokter, Fakultas Kedokteran Universitas Udayana

(gayathrie12@gmail.com)

\section{ABSTRAK}

CT ekspirasi resolusi tinggi merupakan pelengkap CT inspirasi resolusi tinggi dalam mendiagnosis penyakit paru yang difus. Teknik ini memperlihatkan adanya perubahan-perubahan dinamik pada penipisan paru yang dihubungkan dengan beberapa faktor, seperti: jumlah udara dalam alveoli, interstitium paru, dan volume darah dalam paru. Teknik ini sangat sensitif untuk mendeteksi sumbatan jalan nafas yang kecil. Dengan mengkombinasikan CT inspirasi resolusi tinggi dengan CT ekspirasi resolusi tinggi kita dapat lebih memahami mekanisme penipisan paru yang tidak homogen, serta bisa mendiagnosis penyakit paru difus dengan lebih baik.

\section{PENDAHULUAN}

CT inspirasi resolusi tinggi biasanya dilakukan pada akhir inspirasi penuh dengan jarak paralel 1-2 mm dan jarak scan $10 \mathrm{~mm}$. CT ekspirasi resolusi tinggi diambil pada akhir ekspirasi penuh dengan kolimasi yang tipis. Biasanya scan mengambil 2-6 potongan pada preselected level atau pada daerah tertentu yang diinginkan sesuai dengan tujuan penelitian. Rekonstruksi dengan algoritma frekuensi tinggi diharuskan. Oleh karena paru-paru bisa mempelihatkan gambaran udara yang terperangkap (air trapping) yang tidak terduga saat ekspirasi, maka kami merekomendasikan penggunaan CT ekspirasi secara rutin pada preselected level bahkan pada pasien dengan CT inspirasi yang normal.

\section{CT Ekspirasi Resolusi Tinggi}

Penipisan paru yang tidak homogen seringkali ditemukan pada pasien dengan penyakit paru yang difus. Pada jenis pasien tersebut bisa ditemukan gambaran penipisan ground glass, perfusi mosaic karena jalan nafas yang abnormal, atau perfusi mosaic karena gangguan vaskuler. CT ekspirasi mungkin bisa digunakan untuk membedakan kasus-kasus tersebut

CT inspirasi kadang-kadang bisa membedakan ketiga kelainan yang mengakibatkan penipisan paru inhomogen tersebut. Misalnya, gambaran pembuluh darah kecil pada area bawah biasanya ditemukan pada kelainan perfusi mosaik, terlepas dari penyebabnya (misalnya udara yang terperangkap ataukah obstruksi vaskular). Gambaran pembuluh darah dengan berbagai ukuran bisa ditemukan pada penipisan oleh karena opasitas ground glass (gambar.1\&2). Ditemukannya bronkiektasis pada area penipisan yang rendah menunjukkan perfusi mosaik oleh karena air-trapping. Akan tetapi abnormalitas yang terlihat pada CT inspirasi tidak selalu mengindikasikan sebuah kelainan, dan sesuai pengalaman kami tidak bisa digunakan untuk menetapkan suatu diagnosis (gambar.3). 

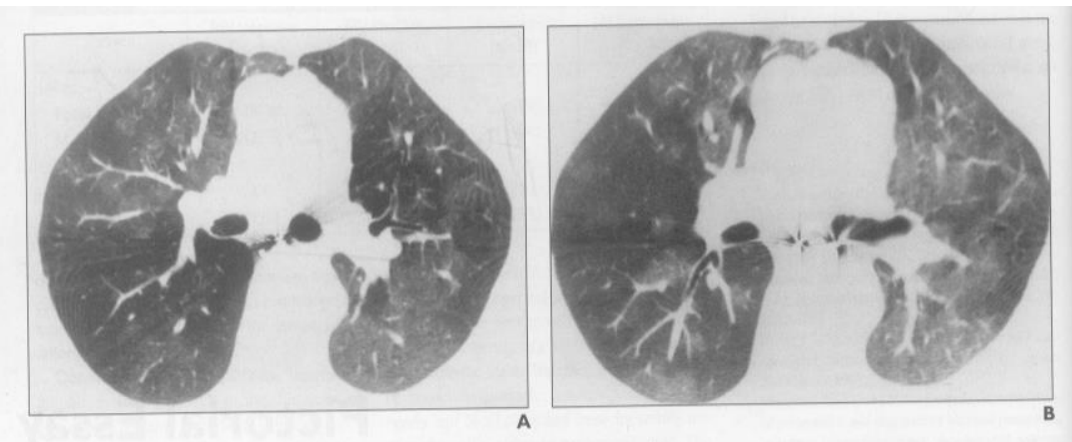

Fig. 1.-43-year-old woman with bronchiolitis obititerans after bilateral lung transplantation.

Whe areas appear smaller than those in high-attenuation areas, suggesting mosaic

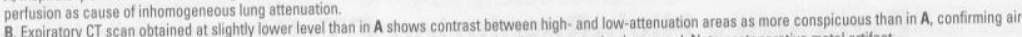
B. Expiratory CT scan obtained at slightly lower level than in A shows contrast between high- and low-attenuation areas as more conspicuous than
trapping in low-attenuation areas. Area of normal lung shows decrease in volume as lung attenuation increased. Note postoperative metal artifact.

$$
\text { (1) }
$$
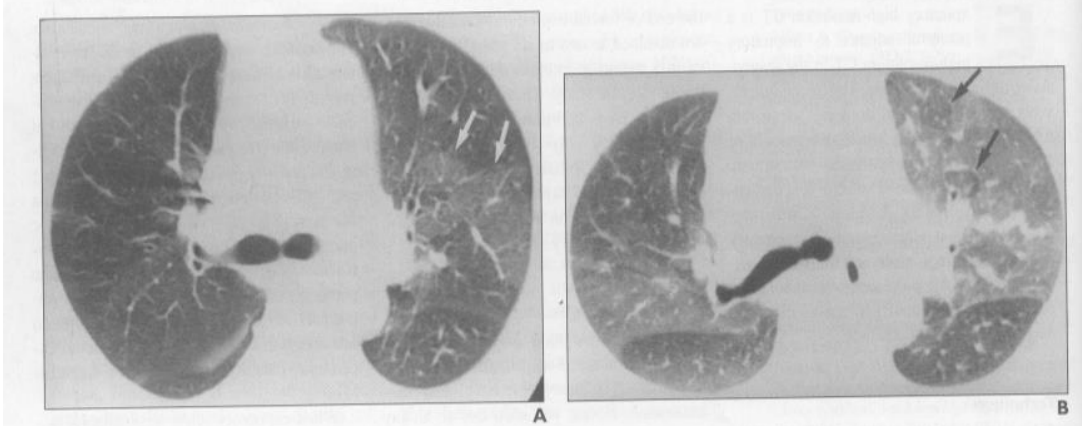

Fig. 2-51-year-old woman with chronic pulmonary thromboembolism and pulmonary hypertension.
A.0ninspiratory CT scan, mosaic perfusion is identified with disparity in vessel size. Left lung shows higher attenuation and larger vessels than right lung. Localized area of high attenuation is noted in left upper lobe (arrows), which may be chronically hyperpertused area. B. Expiratory CT scan shows normal increase of lung attenuation and decrease of lung volume in both high- and low-attenuation areas, with exceptiton of some small arfas

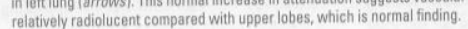

Ketika CT ekspirasi tersedia, kita bisa membedakan penyebab penipisan inhomogen oleh karena perfusi mosaik pada air-trapping dengan penyebab lainnya. Kegunaan diagnosis CT ekspirasi bisa lebih ditingkatkan lagi mengingat fakta bahwa gambaran parenkim paru normal pada pasien dengan penipisan ground glass ataupun dengan konsolidasi memperlihatkan area udara yang terperangkap (air-trapping). Gambaran ini bisa dilihat pada kasus bronkopneumonia, pneumonitis hipersensitivitas, sarkoidosis, hambatan jalan nafas konkomitan, dan penyakit paru infiltratif (gambar.4). 


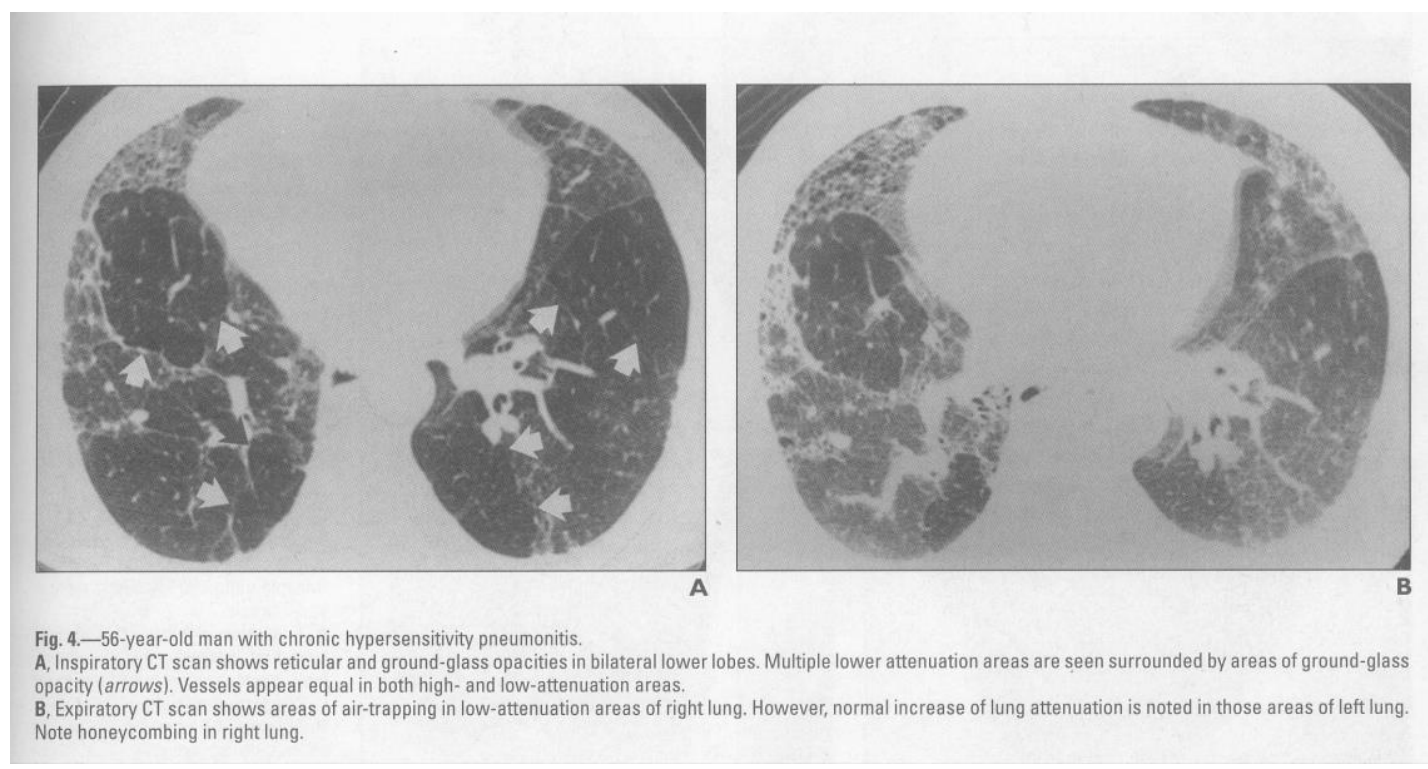

\section{Air-Trapping pada Jenis Paru Normal Lainnya}

Air-trapping bisa juga terlihat pada pasien dengan CT inspirasi yang normal, hal ini dilaporkan pada $20 \%$ yang secara klinis diperkirakan mengalami penyakit hambatan jalan nafas kronik [3]. Diagnosis banding pada kejadian seperti ini meliputi bronkitis (baik akut maupun kronik) (gambar.5), asma bronkiale, bronkiolitis obliteran (gambar.6), sarcoidosis (gambar.7), pneumonitis
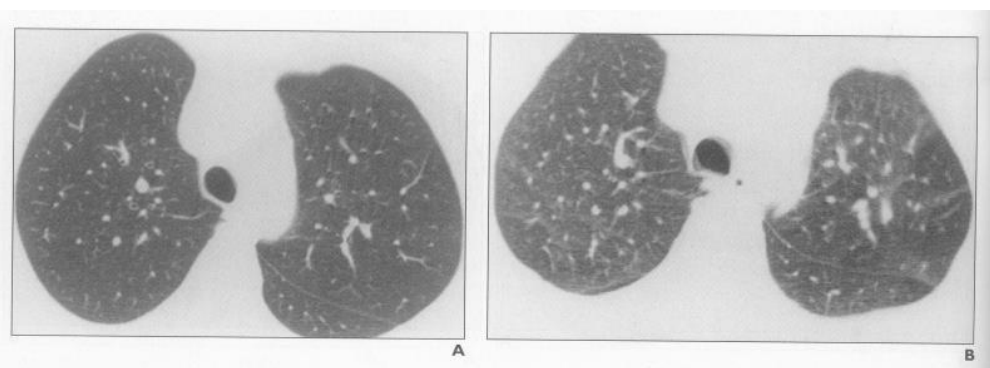

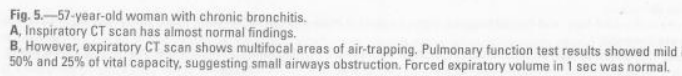
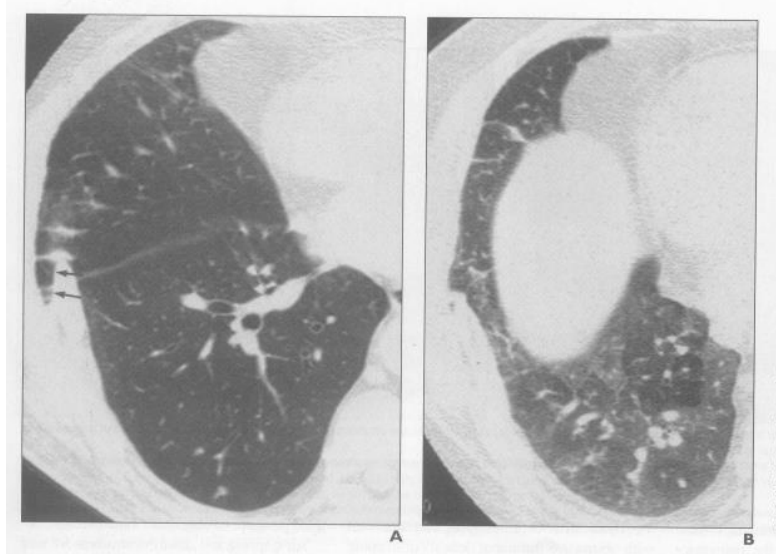

hipersensitivitas, dan paru perokok [4]. Pada pasien dengan penyakit ini, hasil tes fungsi paru menunjukkan hasil yang intermediet, baik pada kontrol yang normal hingga yang menunjukkan airtrapping dan yang menunjukkan abnormalitas pada CT inspirasi [4]. Pada kasus tertentu, CT ekspirasi menunjukkan penyakit paru obstruksi pada stadium awal, walaupun tes fungsi paru normal.

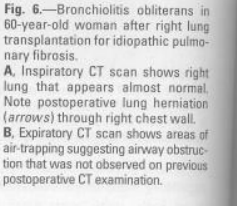




\section{Air-Trapping pada Penyakit Paru Difus}

CT ekspirasi sangat sensitif untuk mendeteksi air-trapping yang merupakan tanda definitif dari obstruksi jalan nafas. Air-trapping sering ditemukan pada bronkiektasis dan sering mendahului berkembangnya overt bronchiectasis (gambar. 8 dan 9). Area dari air-trapping ini berhubungan dengan penurunan fungsi obstruktif. Air-trapping lebih sering terdapat di area mucoid daripada di area yang tidak terdapat mucoid.

Pada bronkiolitis obliterans, CT ekspirasi mampu mendeteksi dini air-trapping sebelum berkembang kelainan-kelainan lain yang tercatat pada inspiratory scan dan ini sangat berguna sebagai deteksi dini pada penyakit ini setelah transplantasi paru. Air-trapping yang luas merupakan faktor prediktor yang baik dari penurunan fungsi obstruktif.

Air-trapping dan obstruksi udara tidak hanya terlihat pada penyakit saluran pernafasan tetapi juga pada penyakit paru interstisial, termasuk pneumonitis hipersensitivitas dan sarkoidosis [5].

Pada pneumonitis hipersensitivitas, adanya infiltrat inflamasi yang bersifat kronis disepanjang saluran pernafasan yang sempit (bronkiolitis selular) menyebabkan bronkiolar menyempit, dan air-trapping sering ditemukan pada banyak kasus [6] (gambar. 10).

Sarkoidosis merupakan kelainan pada interstisium dan biasanya menunjukkan penurunan fungsi restriktif. Bagaimanapun, penyumbatan saluran pernafasan kecil sekarang dipikirkan sebagai gambaran yang penting [7]. Penekanan dari jalan nafas oleh pembesaran kelenjar limpa, adanya lesi endobronkial , jaringan parut fibrotik dari lesi endobronkial dan penyimpangan bronkial dengan fibrosis peribronkial dan abnormalitas dari saluran pernafasan kecil diperkirakan menyebabkan penyempitan jalan nafas (gambar. 11).
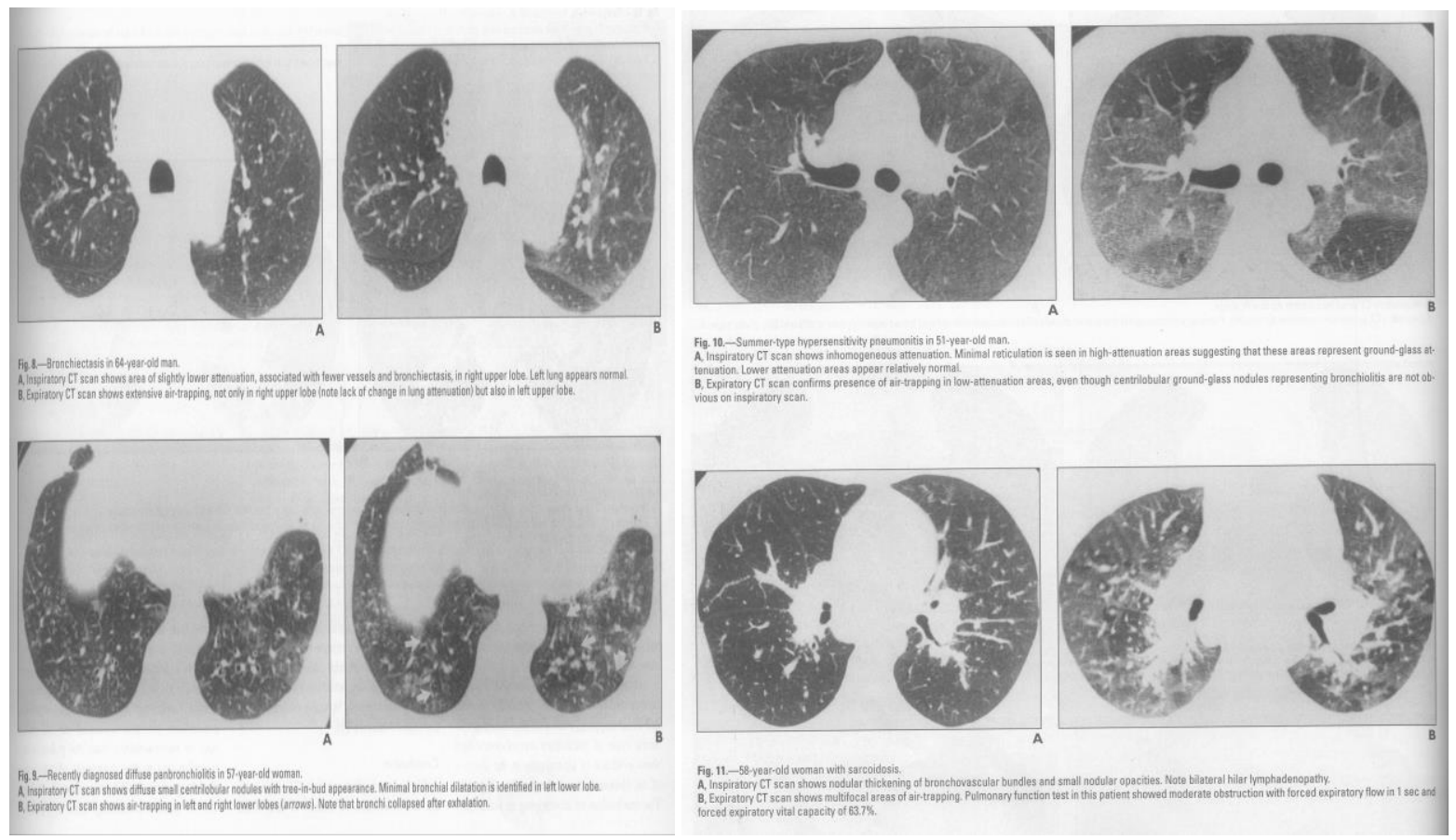


\section{Kelemahan dari CT Ekspirasi Resolusi Tinggi}

Efektifitas dari tehnik ini bergantung pada kerjasama pasien. Ekshalasi yang tidak cukup mengakibatkan peningkatan yang sedikit dari lung attenuation; ini mungkin disalahartikan dengan diffuse-air trapping.

CT Ekspirasi diperkirakan lebih sensitif untuk mendeteksi penurunan obstruktif daripada tes fungsi paru, tetapi ini tidak selalu benar. Banyak pasien yang menunjukkan penurunan fungsi obstruktif tidak memperlihatkan airtrapping. Ini sebagian karena tes fungsi paru memperlihatkan fungsi paru secara keseluruhan. Sebaliknya, air-trapping pada CT scan dapat menunjukkan lebih banyak abnormalitas lokal.
Perfusi mosaik akibat obstruksi pembuluh darah tidak selalu dapat dibedakan dengan airtrapping meskipun dengan menggunakan CT ekspirasi. Beberapa kasus tromboemboli pada paru menunjukkan adanya air-trapping tanpa kelainan saluran nafas yang nyata. Mekanisme airtrapping pada tromboemboli paru ini diakibatkan oleh emboli yang menyebabkan pelepasan mediator humoral seperti histamin dan serotonin oleh platelet yang bersirkulasi dan pada akhirnya dapat menyebabkan bronkokonstriksi sementara dan menyeluruh juga suara mengi seperti pada asma.
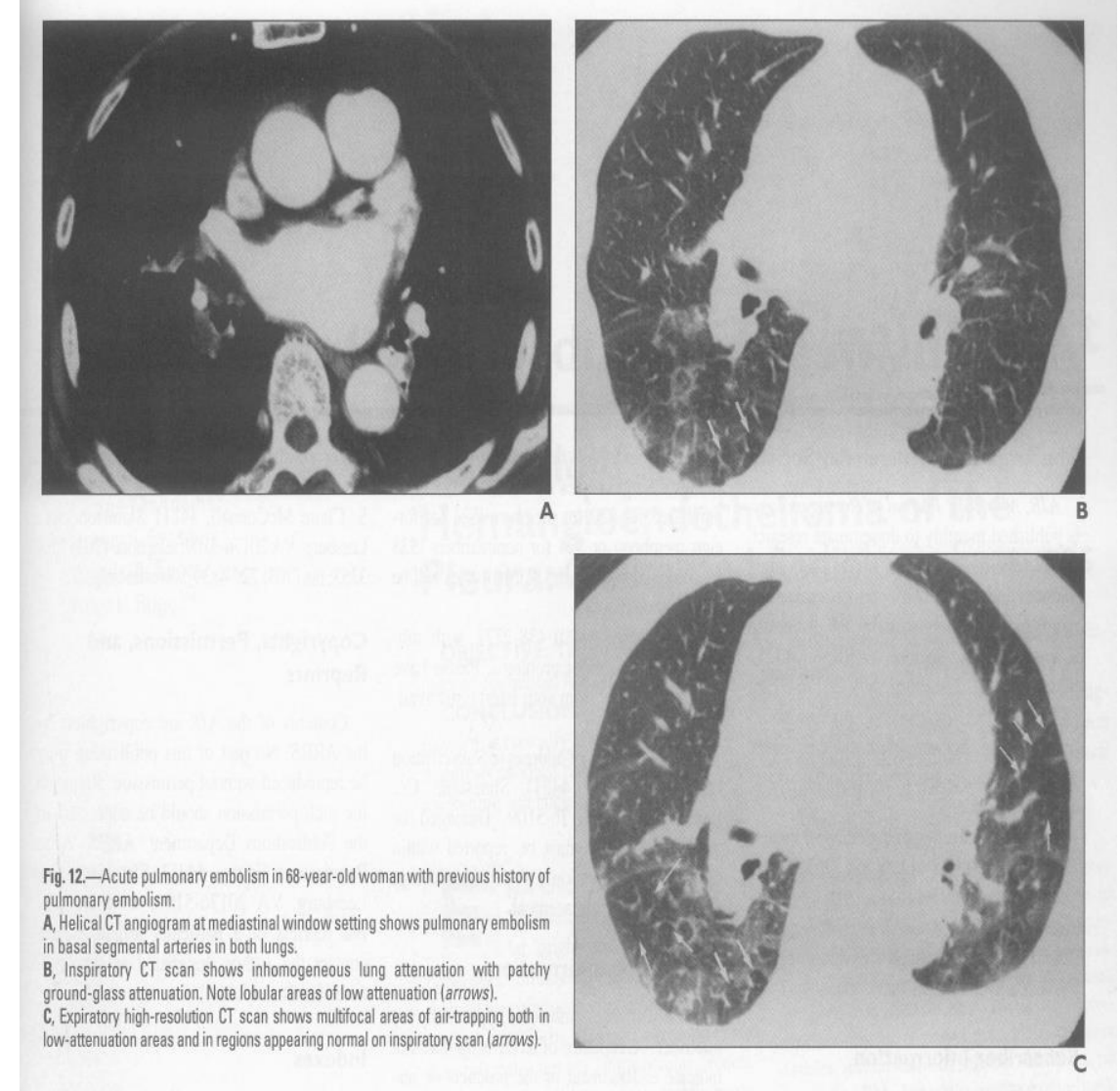

yang bersifat inhomogen. Air-trapping pada pasien dengan gambaran yang normal saat inspirasi merupakan hal yang sering ditemukan. CT 
ekspirasi dapat memperlihatkan tidak hanya airtrapping yang menyeluruh tapi juga air-trapping yang bersifat lokal. CT ekspirasi mungkin lebih sensitif dibandingkan dengan tes fungsi paru dalam hal diagnosis Penyakit Paru Obstruktif. Penulis merekomendasikan penggunaan gabungan CT saat inspirasi dan ekspirasi resolusi tinggi untuk menegakkan diagnosis penyakit paru difus.

Daftar Pustaka

1. Arakawa H, Webb WR, McCowin M, Katsou G, Lee KN, Seitz RF. Inhomogeneous lung attenuation at thin-section CT: diagnostic value of expiratory scans. Radiology 1998; 206:89-94 [Medline]

2. Im JG, Kim SH, Chung MJ, Koo JM, Han MC. Lobular low attenuation of the lung parenchyma on CT: evaluation of forty-eight patients. J Comput Assist Tomogr 1996; 20:756-762 [CrossRef] [Medline]

3. Lucidarme O, Coche E, Cluzel P, Mourey-Gerosa I, Howarth N, Grenier P. Expiratory CT scans for chronic airway disease: correlation with pulmonary function test results. AJR 1998; 170:301-307 [Abstract] [Medline]

4. Arakawa $H$, Webb WR. Air trapping on expiratory high-resolution CT scans in the absence of inspiratory scan abnormalities: correlation with pulmonary function tests and differential diagnosis. AJR 1998; 170:1349-1353 [Abstract] [Medline]

5. Arakawa $H$, Webb WR. Expiratory highresolution CT scan. Radiol Clin North Am 1998; 36:189-209 [CrossRef] [Medline]

6. Hansell DM, Wells AU, Padley SP, Muller NL. Hypersensitivity pneumonitis: correlation of individual CT patterns with functional abnormalities. Radiology 1996; 199:123-128 [CrossRef] [Medline]
7. Lewis MI, Horak DA. Airflow obstruction in sarcoidosis (editorial). Chest 1987; 92:582-584 [Medline]

8. Webster JR Jr, Saadeh GAMBAR, Eggum PR, Suker JR. Wheezing due to pulmonary embolism: treatment with heparin. N Engl J Med 1966; 274:931-933 [CrossRef] [Medline] Read More: http://www.ajronline.org/doi/full/10.2214/ajr.175 .6 .1751537 